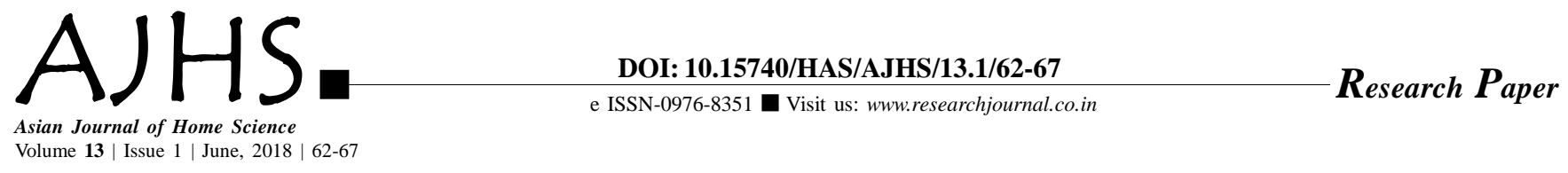

\title{
Level of aspiration of adolescent boys of working and non-working mothers
}

Mukta Garg and Beena Upadhyay

Received: 09.12.2017; Revised: 19.03.2018; Accepted: 05.04.2018

See end of the paper for authors' affiliations Mukta Garg

Department of Human Development and Family Study, College of Home Science, C.S.A. University of Agriculture and Technology, Kanpur (U.P.) India
ABSTRACT : A person's level of aspirations is an important aspect of his personality. A fruitful approach to study of self-enhancement has been the concept of aspiration level. The purpose of this study was to find out and compare the level of aspiration (GDS, ADS, and NTRS) between the adolescents of working and non working mothers and to find out the effect of age, caste and income of the family on Various Scores of Level of aspiration (GDS, ADS and NTR). The study was conducted in the Faizabad of Uttar Pradesh. A sample comprised of 60 adolescent boys out of which 30 adolescents of working mothers and 30 adolescents of non- working mothers were selected through random cum purposive sampling. A standardized scale of level of aspiration developed by Dr. M.A. Bhargawa and Dr. M.A. Shah was used to collect the information. It was found that GDS and NTR of 17 years of boys was higher than 16 years, and boys of non-working mothers were having higher Mean values on goal discrepancy score and attainment discrepancy score in comparison to respondents of working mothers whereas respondents of working mothers were having high mean value of number of time the goal reach score in comparison to respondents of non-working mothers. Thus, it was concluded that the adolescents of non working mothers sets their goal higher than their actual performance, where as the adolescents of working mothers reach to their target goal most of the time .

KEY WORDS: Adolescent boys, Non-working mothers, Scale, GDS, ADS, NTRS

- HOW TO CITE THIS PAPER : Garg, Mukta and Upadhyay, Beena (2018). Level of aspiration of adolescent boys of working and non-working mothers. Asian J. Home Sci., 13 (1) : 62-67, DOI: 10.15740/ HAS/AJHS/13.1/62-67. Copyright@ 2018: Hind Agri-Horticultural Society.' 